\section{Cooperative Extension: A Model of Science-Practice Integration for Ecosystem Restoration}

\author{
Erica David, ${ }^{1,2, \star}$ Kingsley W. Dixon, ${ }^{1,2,3}$ and Myles H.M. Menz ${ }^{4}$
}

Restoration ecology is a science, driven by practical application. Despite the well-recognized disconnect between the science and practice of ecological restoration, there is a lack of practical solutions. In 2014, US agriculture marked the 100th anniversary of the Cooperative Extension Service, providing a timely reminder that the divide between science and practice can be bridged successfully. Major restoration efforts are underway across the globe and integrated science-practice communication is required to avoid project failure and a significant waste of resources. Here, we propose a three-tiered approach, reemphasizing the integration of science-based practice in restoration utilizing the structure, function, and potential for success of the Cooperative Extension Service of the US Department of Agriculture (USDA) as a model for connecting science and practice in ecosystem restoration.

The Challenge: Bridging the Science-Practice Gap

The separation between science and practice is a long-recognized concern in restoration ecology (e.g., [1,2]), a US\$1 trillion a year industry [3]. Streamlining information dissemination between science and practice would significantly improve the efficiency of ecosystem restoration projects at both local and larger scales and, thus, progress towards reaching global restoration targets $[1,2,4]$. The number of papers published in restoration ecology continues to flourish, far outweighing the increase in successful on-ground applications. For example, a survey of stream-restoration practitioners found that $<1 \%$ of over 300 restoration projects utilized science-backed practice [5]. Practitioners harbour the funding and work force to make significant contributions to restored landscapes; however, access to sound science and bestpractice methods is often limited, causing many of these projects to fail to achieve their full capacity. The two cultures draw upon conflicting modes of inquiry, where science requires time, statistically sound replication, and controls, while practice often demands immediate, economical, and best-guess approaches [6]. This disconnect is fuelled by the compartmentalization of literature pools, because practitioner's 'gray literature' is not always considered rigorous enough to be included and cited within scientific literature, while limited access to scientific literature may prevent practitioners from consistently turning to newly published science when developing restoration protocols [6-8]. Developing a more integrated system holds the potential to benefit both parties [9]. A closer working relation increases the funding pool and provides a diverse community of perspectives. The infrastructure of industry can allow for research projects at an expanded scale, while the incorporation of science can bolster the prestige and resilience of a program, feeding back to improve future restoration efforts [10].
Trends

The gap between science and practice is a long-recognized concern in restoration ecology, but there is a lack of practical solutions.

Without successful communication, significant resources will be wasted on potentially misguided global restoration efforts.

The Cooperative Extension Service successfully bridged the science-practice gap in American agriculture.

Here, we discuss how such a framework could be applied to bridge the science-practice gap in restoration ecology.

${ }^{1}$ Kings Park and Botanic Garden, West Perth, WA 6005, Australia ${ }^{2}$ University of Western Australia, School of Plant Biology, Crawley, WA 6009, Australia

${ }^{3}$ Department of Environment and Agriculture, Curtin University, Bentley, WA 6012, Australia

${ }^{4}$ Institute of Ecology and Evolution, University of Bern, Bern 3012,

Switzerland

${ }^{*}$ Correspondence:

ericadavid89@gmail.com (E. David). 
Connecting science to practice is an active point of debate across a broad range of industries, from medicine [11], to education [12], to social science, agriculture, and conservation biology [7]; and remains a challenge in most industries. However, for US agriculture, a solution was found that could serve as an exceptional model for application across industries. The USDA Cooperative Extension Service (see Glossary) 'takes the science to the people', effectively transferring science to farmers and ranchers throughout the nation (USA)'. Can this same model work for restoration ecology?

Here, we propose a three-tiered approach to improving the science basis to ecological restoration: (i) expand the use of adaptive management in restoration ecological programs where there is robust ecological restoration science presence; (ii) utilize existing integrating frameworks (e.g., in the USA, the Cooperative Extension Service; the global Chapter network of The Society for Ecological Restoration), to improve the knowledge base and stakeholder integration in the restoration science and practice interface; and (iii) for many countries, particularly in developing economies without pre-existing capacity or infrastructure as in tiers (i) and (ii), creation of a restoration extension service (RES) based on the form, function, and structure of the successful and long-standing Cooperative Extension Service of the USDA, may be appropriate and necessary.

Humanity sits today at a crossroads in history, where industrialization has had a mass detrimental effect on the environment. From global warming and desertification to losses in biodiversity, great challenges are threatening ecosystems and the services we depend upon in every corner of the globe (e.g., [13,14]). All the while, a generational shift has placed increasing importance on environmental awareness; with increases in green technology, the launch of several global-scale environmental initiatives (Figure 1), and pressure from global mandates to develop innovative methods of environmental conservation, our mind set has begun to shift. We must seize this moment to enter a new paradigm, building the infrastructure necessary to fuel global restoration programs and promote a future of environmental stewardship and sustainability.

\section{Cooperative Extension Service as a Model for Restoration Ecology}

For many areas of the world where ecological restoration is critically required, there may not be the science infrastructure or adaptive management capabilities to support knowledge-driven restoration practice. The USA faced a similar dilemma in agriculture, where the science of production systems was disconnected from the practitioner (farming) community and the concept of the agricultural Cooperative Extension Service was developed. The Cooperative Extension Service celebrated its centenary in 2014 and has been connecting the US farming community with research organizations since the early 1900s [15]. Before the inception of the Cooperative Extension Service, American agriculture exhibited a similar discord between science and practice, as is seen in restoration ecology today. The movement began with the Morrill Act in 1862 (Morrill Act of 1862, Act of July 2, 1887, ch. 130, 7 U.S.C. 301 et seq.), which targeted education for all, regardless of socioeconomic standing. The Hatch Act of 1887 (Hatch Act of 1887, Act of March 2, 1887, ch. 24 Stat. 440, 7 U.S.C. 361a et seq.) expanded this, developing research centres to fuel land grant colleges with new information to teach. The Smith Lever Act of 1914, formed the Cooperative Extension Service 'to aid in diffusing among the people of the United States useful and practical information on subjects relating to agriculture' (Smith-Lever Act, Act of May 8, 1914, ch. 79, 38 Stat. 372, 7 U.S.C. 341 et seq.). Extension offices were established in each county, providing a local link for farmers and ranchers. As the Cooperative Extension Service celebrates its 100th anniversary, the program has continued to grow and expand to meet the demands of the modern world [15]. With nearly 3000 offices nationwide, the Cooperative Extension Service has become a global standard of success in scientific information dissemination.

\section{Glossary}

Adaptive management: a cyclic, structured, feedback research model used in environmental management to continually reassess and fine-tune practice methods using the following steps: (i) conceptualize; (ii) plan; (iii) implement; (iv) adapt; and (v) share learning.

Cooperative Extension Service: an agency dedicated to dissemination of information in agricultural science through a network of extension offices throughout the USA, run by the USDA.

Participatory action research: a research model that works extensively with practitioner and community participation in the conceptualization, monitoring, and analysis stages, encouraging greater ownership and application of novel methods and technologies Restoration Extension Service (RES): a global organization proposed by the authors as a solution to bridging science and practice in restoration ecology, modeled after the Cooperative Extension Service. 


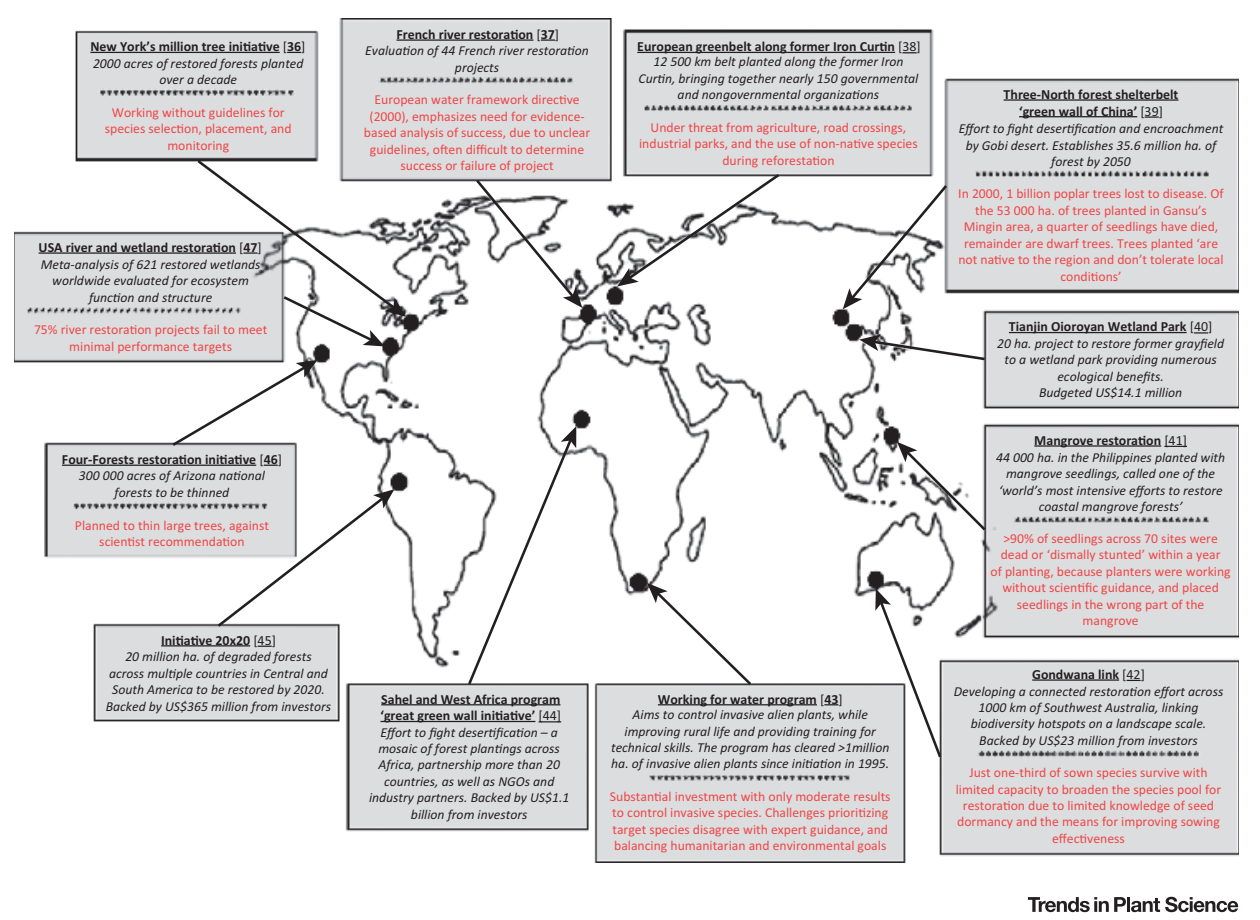

Figure 1. A Global Overview of Landscape-Scale Restoration Projects. Shortcomings and failures of current projects are shown in red and are due to a lack of communication and the failure to bridge the science-practice gap [Conniff, R. (2014) Rebuilding the natural world: a shift in ecological restoration ${ }^{\text {vij }}$ Coordination Group of the European Green Belt Initiative (2015) $)^{\mathrm{vii}}$; LandscapePerformance (2014) Tianjin Qiaoyuan Park: The Adaptation Palettes viii; The World Bank. (2014) Transforming the Sahel: Supporting the Great Green Wall Initiative ${ }^{i x}$; World Resources Institute (2014) Initiative 20x20* Schulke, T. (2013) Forest Service Again Jeopardizing Major Forest Restoration Project in Arizona $\left.{ }^{\times}\right]$[37-42]. An increase in the number of global restoration initiatives has led to countries pledging large amounts of funding to large-scale restoration projects. However, these projects are often implemented without sufficient prior knowledge and capacity to achieve the specific goals set.

\section{Why Extension Works}

Developing a RES that mimics the model set out by Cooperative Extension Service in American agriculture, both science and industry can capitalize on the use of time-tested infrastructure and proven experiential learning techniques led by extension agents. The cornerstone of the extension concept is the human factor [16]. An extension agent provides a link to synthesize scientific results generated by academia into a form both accessible and practical for on-ground application. The global restoration community must harness the power of the extension model; becoming architects of learning to integrate, educate, and empower.

Integrate: Developing a Centralized, Ready-Access Platform

The Cooperative Extension Service provides an integrated hierarchal infrastructure, where local offices work closely with farmers, providing a trusted and readily accessible personal contact and portal with the ability to customize services to relevant local issues. Each local office is connected to a state and national office, which serve as the primary connection to agricultural science, and allow coordination of efforts across regions. This infrastructure facilitates information flow. Scientists publish research, which is then synthesized by the Extension Agent and presented in a practical, readily accessible form to the practitioner (i.e., through the release of a newsletter or hands-on demonstration) (Figure 2). Similar functions are successfully performed by other agricultural extension organizations elsewhere in the world, such as Agridea in Switzerlandii. Furthermore, the agent constantly assesses and gathers concerns from the farmer 


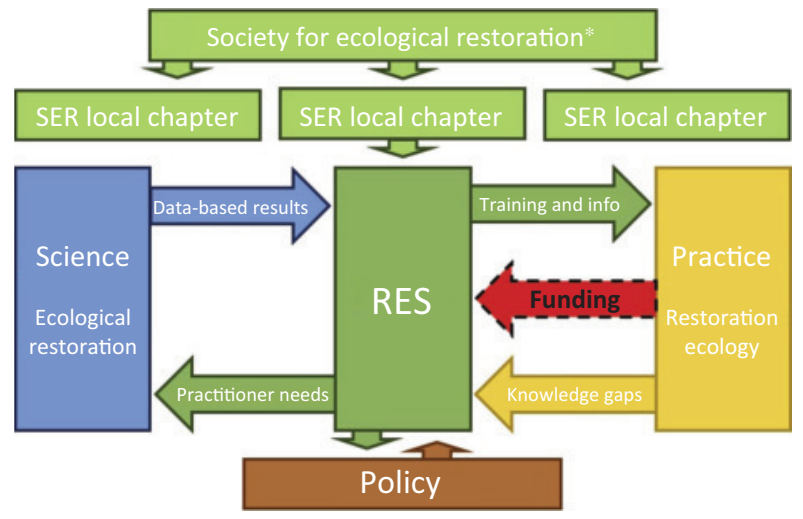

Trends in Plant Science

Figure 2. A Schematic Representation of the Function of the Proposed Restoration Extension Service (RES). The proposed RES could be closely linked to the pre-existing hierarchical structure of the Society for Ecological Restoration (SER), which already has local chapter offices in many regions of the globe. Although other nongovernmental organization (NGO) groups are involved in ecological restoration, SER is the only multinational NGO that is specifically organized and mandated by its membership for the accumulation, sorting, and dissemination of restoration knowledge across the science-practice interface $\left({ }^{*}\right)$. The function of the RES would be to synthesize the results of data-based science and transfer these to practitioners in an accessible format, such as via workshops and information sheets. In turn, practitioners have an avenue of communication, via the RES, to highlight knowledge gaps and areas of restoration ecology in need of urgent further study, which can then be communicated to scientists. The RES can also perform an additional vital function, by communicating with policy makers of the latest state of knowledge and identified best practice. Furthermore, we recognize the vital role that some end-user practitioners, such as mining companies, can have via the targeted injection of much-needed funding into the RES and science.

to communicate to the university or research organization, ensuring science remains directed towards real-world issues (Figure 2).

\section{Educate: Experiential Learning}

Seaman Knapp, father of extension, stated in a letter in 1910 'What a man sees or hears he may doubt but what he does he cannot doubt. . .' [17]. In the early years of extension, Knapp travelled cross-country, educating farmers through hands-on farm demonstrations (Box 1). To this day, demonstration remains the preferred mode of information dissemination [16]. Although dated, Howell and Habron [18] found that $77 \%$ of landowners supported written media, $54 \%$ preferred face-to-face interactions, while only $19 \%$ supported Internet education. More contemporary studies indicate that the trend still holds [19], because a survey of extension agents and producers identified farm demonstrations as the number one preferred method of learning, while Internet was identified as one of the least-preferred methods of learning [20]. Online learning platforms lack social and cognitive presence, and deprive the learner the opportunity to interact within a community of inquiry [21]. We recognise technology as an integral component of modern-day education; however, online learning must be paired with experiential learning and face-to-face interactions to insure the facilitation of discussion and implementation of novel technologies. Within the Cooperative Extension Service, $4 \mathrm{H}$, a youth development program, globally recognized for its ability to engage students in active learning and development of individual agricultural projects, additionally offers a strong model for enhancing youth involve-

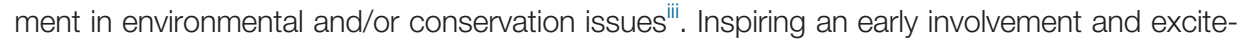
ment surrounding environmental issues is vital to the continuation of the field, because it will foster a sustained interest in the industry for future generations. 


\section{Box 1. The Teaching Philosophy of Dr Seaman A. Knapp: The Father of Extension}

Born December 16, 1833 in Schroon, New York, Seaman A. Knapp grew up on the family farm. After graduating with his BA from Union College, New York in 1856, he and his family moved to the Midwest, where he continued pursuing his interest in agriculture. His firm belief in the importance of hands-on learning led to the first Farmer's Institutes, a series of traveling demonstrations teaching farmers best-practice methods (Figure I). He began training other educators as extension agents, who would help to diffuse the information developed by universities to the people.

The men who act as field agents must be practical farmers, no use in sending a carpenter to tell a tailor how to make a coat, even if he is pretty well read up on coats. The tailor won't follow. The farmer must be a recognized leader, progressive, influential and able to carry public opinion with him. Public opinion is brought into harmony and made forceful by the support of the press and the cooperation of the best farmers and the leading merchants and bankers.

Knapp continually stressed the need for farmers to see and experience results, stating: 'It is not sufficient to tell the farmer that his method is not the best. He must be shown the best methods. The appeal must be made through his eye. He will quickly accept new principles and practices if their value is demonstrated to him under the environment in which he lives...'. Knapp's use of experiential learning was key to increasing the application of new practices in American agriculture. He recognized that 'There are some people in every community who are ready to take issue with everything which may be offered. They can not argue against results. Lessons written upon the ground in the forms of better crops and live stock can not fail to be convincing.' Knapp's teaching philosophy is relevant, both in modern times, and across industries. Just as a farmer engaged in the early cooperative extension programs could see significant increases to their own crop or livestock returns under guidance of the extension agents, so too can today's restoration practitioners see improvements to their restoration programs, on-site and directly relevant to their situation, given guidance from our proposed RES Agents. By continuing Knapp's mantra of 'learning by doing', RES agents can use experiential learning and participatory action research to more effectively apply best practice methods in restoration. (Quotes taken from [19]).

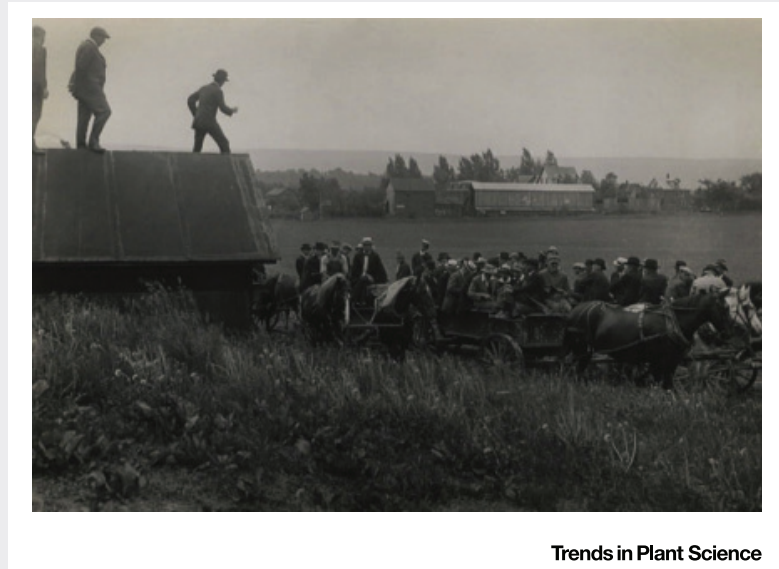

Figure I. Community Members Gather for a Farm Demonstration. Early implementation of Farmer's Institutes at the turn of the 20th century allowed for cooperative extension agents to demonstrate best practice methods to farmers. Reproduced, with permission, from Penn State University Archives.

Empower: Providing a Platform for Community-Driven Restoration Research

Utilizing the Cooperative Extension Service model to engage practitioners and scientists in integrated practices, such as participatory action research and adaptive management, will greatly enhance our ability to generate implementation-ready research for restoration. These integrated learning models work to acquire knowledge in the context of application, and have been implemented with great success in several agricultural [22-24], and environmental systems globally [25-27]. More colloquially known as 'on-farm research', or 'farm-driven research', the participatory action research scheme extends the concepts of experiential learning to a state of 'action learning', engaging the practitioner at an early stage of knowledge generation [28,29]. Following the adaptive management cycle allows for continued improvement and adjustment to management programs and policies as needed $[25-27,30]$. This facilitates participation and a 
sense of ownership by stakeholders and practitioners, crucial to increasing the likelihood of knowledge implementation and the long-term acceptance of innovations [29,31-34]. The application of participatory action research additionally allows remote, at-risk, and underdeveloped regions to become empowered with the sense of ownership, confidence, and civic engagement gained from community-based restoration [35]. The Cooperative Extension Service reaches beyond barriers of Internet access, literacy, and poverty, bringing technologies to those who need it most. For communities and stakeholder groups throughout the globe, the development of a RES has potential for great successes; integrating communication through a proven hierarchical infrastructure, educating using the highly preferred experiential learning model, and empowering participants through participatory action research and community-driven restoration. Importantly, through a RES, the (over) abundance of theory-based restoration ecological publications would have an audience prepared to test and adapt theory into practice-based outcomes. Furthermore, increasing participation of practitioners directs the research demand towards 'real-world' issues and raises discussion during study addressing applicability and implementation.

\section{A Picture of the Restoration Extension Service}

Cooperative Extension successfully interwove science and practice for the US agricultural industry. A RES holds similar potential to unite science and practice in ecological restoration. Cabin and colleagues [36] called for the development of such an organization; however, no further explanation was given and little has been done towards implementation.

While the development of a RES could take many forms, we propose closely modeling the Cooperative Extension Service framework, and attaching the program to pre-existing structures, following a three-tiered system. For well-established restoration programs with a strong, active science presence, continued efforts should be made to reward and enhance integrated practice (such as participatory action research and adaptive management), promoting continued use of science-based practice in on-the-ground projects. For programs with access to the infrastructure and resources of the Cooperative Extension Service in the USA, we propose developing an enhanced RES branch, expanding the knowledge base and connecting key restoration stakeholders, therefore facilitating integrated, science-based restoration practice. For programs in countries without a pre-existing framework, the development of a new RES infrastructure may be required. This boundary organization should closely follow the role and function of the Cooperative Extension Service, providing resources, personnel, and structure to access and mine current science for novel practices, convert these results into a practitioner-accessible form, and efficiently disseminate the information through experiential learning and participatory action research methods. To maintain a central umbrella body and strong cross-project communication, we recommend utilizing a pre-existing international structure, such as the global peak body for ecological restoration, The Society for Ecological Restoration (SER; Figure 2). An organization such as SER offers a pre-existing hierarchical structure to work from, with chapter, state, national, and international tiersiv. Furthermore, SER has a large and active membership of scientists and practitioners from over 70 countries, facilitating initial awareness of the new program, and increasing user willingness. Previous efforts by SER to enhance the scientist-practitioner relation serve as stepping-stones towards the fully optimized RES of the future. The journal Restoration Ecology and its requirement to include an 'implications for practice' section began to open lines of communication. Launch of the Global Restoration Network ${ }^{\vee}$ Internet database provides a searchable, centralized collection of restoration efforts.

The Global Restoration Network provides a starting point for the development of a more comprehensive RES, capable of generating positive change in restoration around the globe. The Global Restoration Network webpage provides a point of access, and a comprehensive centralized database, yet it cannot stand on its own. Therefore, it is the role of the RES to facilitate 
implementation of this information, synthesizing research, and place it into the hands of practitioners. Without the partnership of RES offices, and face-to-face interaction with extension agents, dissemination of scientific knowledge and novel technologies will continue to struggle. The RES agent, similar to the extension agent of the Cooperative Extension Service, would be responsible for synthesizing data into accessible bulletins and demonstrations, and would work with practitioners to provide relevant research topics to universities and research institutes for investigation (Figure 2) (see Outstanding Questions). We suggest attaching the position to the SER chapter structure, where the 'RES Agent' could become an additional position of the Board of Directors, or could form a secondary responsibility of the current 'General Board Member/ Representative/At Large' positions. To maximize the effectiveness of this role, we recommend making the RES Agent a full-time funded position. While we recognize that most ecological restoration projects are at the local scale, funding possibilities could derive, for example, from resource companies or consortia interested in large-scale restoration projects (Figure 2). By establishing a tangible link between science and practice via local offices and RES agents, a RES will drive restoration ecology on a path to success in meeting global restoration targets in the face of unprecedented global environmental degradation.

\section{Resources}

'www.extension100years.net

ii www.agridea.ch

iii www.alaska4h.org/

iv www.ser.org

${ }^{v}$ www.globalrestorationnetwork.org

vi www.ecology.com/2014/04/08/shift-ecological-restoration/

vii www.europeangreenbelt.org/

viii www landscapeperformance.org/case-study-briefs/tianjin-qiaoyuan-park-the-adaptation-palettes

ix www.worldbank.org/en/region/afr/brief/world-bank-support-for-great-green-wall-initiative

${ }^{x}$ www.wri.org/our-work/project/initiative-20x20

${ }^{x i}$ www.biologicaldiversity.org/news/press_releases/2013/four-forests-restoration-initiative-08-12-2013.html

\section{References}

1. Burbidge, A.H. et al. (2011) Linking science and practice in ecological research and management: how can we do it better? Ecol. Management Restoration 12, 54-60

2. Menz, M.H.M. et al. (2013) Hurdles and opportunities for landscape-scale restoration. Science 339, 526-527

3. Cunningham, S. (2008) reWealth! McGraw Hill

4. Suding, K. et al. (2015) Committing to ecological restoration. Science 348, 638-640

5. Bernhardt, E.S. et al. (2007) Restoring rivers one reach at a time: results from a survey of U.S. river restoration practitioners. Restoration Ecol. 482-493

6. Holling, C.S. (1998) Two cultures of ecology. Conserv. Ecol. 2, 4

7. Arlettaz, R. et al. (2010) From publications to public actions: when conservation biologists bridge the gap between research and implementation. BioScience 60, 835-842

8. Banks, M.A. (2006) Towards a continuum of scholarship: the eventual collapse of the distinction between grey and non-grey literature. Publishing Res. Q. 22, 4-11

9. Suding, K. (2011) Toward an era of restoration in ecology: successes, failures, and opportunities ahead. Annu. Rev. Ecol. Evol. Syst. 42, 465-487

10. Cabin, R.J. (2007) Science-driven restoration: a square grid on a round earth? Restoration Ecol. 15, 1-7

11. Grumbach, K. and Mold, J.W. (2009) A health care cooperative extension service: transforming primary care and community health. JAMA 301, 2589-2591

12. Rogers, E.M. (1992) Prospectus for a cooperative extension system in education. Sci. Commun. 13, 248-255

13. Mora, C. and Sale, P.S. (2011) Ongoing global biodiversity loss and the need to move beyond protected areas: a review of the technical and practical shortcomings of protected areas on land

14. Hooper, D.U. et al. (2012) A global synthesis reveals biodiversity loss as a major driver of ecosystem change. Nature 486, 105-108

15. Gould, F.l. et al. (2014) Cooperative extension: a century of innovation. J. Extension 52,

16. Torock, J. (2009) Experiential learning and cooperative extension: partners in non-formal education for a century and beyond. $\mathrm{J}$. Extension 47, 6

17. Martin, O.B. (1921) The Demonstration Work: Dr. Seaman A. Knapp's Contribution to Civilization, Stratford Co. Publishers

18. Howell, J.L. and Habron, G.B. (2004) Agricultural landowners' lack of preference for internet extension. J. Extension 42, 6

19. Seavey, N.E. and Howell, C.A. (2010) How can we improve information delivery to support conservation and restoration decisions? Biodivers. Conserv. 19, 1261-1267

20. Nelson, C.B. et al. (2009) Information transfer between extension agents and dairy producers. In American Association for Agricultura Education Research Conference Proceedings, pp. 244-256, AAAE

21. Stodel, E.J. et al. (2006) Learners' perspectives on what is missing from online learning; interpretations through the community of inquiry framework. Int. Rev. Res. Open Distance Learn. 7, 3

22. Mandez, V.E. et al. (2013) Agroecology as a transdisiplinary, participatory and action-oriented approach. Agroecology Sustainable Food Syst. 37, 3-18

23. Mackenzie, J. et al. (2012) The value and limitations of participatory action research in methodology. J. Hydrol. 474, 11-21

24. Vermillion, D.L. and Brewer, J.D. (1996) Participatory action research to improve irrigation operations: examples from Indonesia and India. In International Commission on Irrigation and sea. Mar. Ecol. Prog. Ser. 434, 251-266

\section{Outstanding Questions}

What is the current status of largescale restoration projects, with focus on a formal study investigating their success and/or status, and stakeholders' preferred method of communication and learning (across academics, NGOs, industrial practitioners, and community groups)?

How can the use of centralized online databases, brick-and-mortar offices, and face-to-face instruction be incorporated to optimize application of restoration best-practice methods? 
and Drainage (ICID); FAO. Irrigation scheduling: from theory to practice. Proceedings of the ICID/FAO Workshop on Irrigation Scheduling, pp. 241-249, Rome, Italy, 12-13 September 1995pp. 241-249, Rome, Italy, FAO

25. Lee, K.N. (1999) Appraising adaptive management. Cons. Ecol. 3, 3

26. Folke, C. et al. (2002) Resilience and sustainable development: building adaptive capacity in a world of transformations. Ambio 31, 437-440

27. Stringer, L.C. et al. (2006) Unpacking "participation" in the adaptive management of social-ecological systems: a critical review. Ecol. Soc. 11

28. Green, L.W. et al. (2003) Appendix C: Guidelines for Participatory Research in Health Promotion. In Community-Based Participatory Resarch For Health: From Process to Outcomes (Minkler, M. and Wallerstein, N., eds), pp. 419-428, Jossey-Bass

29. Probst, K. et al. (2003) Understanding Participatory Research in the Context of Natural Resource Management - Paradigms, Approaches, and Typologies, Agricultural Research \& Extension Network

30. Linkov, I. et al. (2006) From comparative risk assessment to multicriteria decision analysis and adaptive management: Recent developments and applications. Environ. Int. 32, 1072-1093

31. Israel, B. et al. (1998) Review of community-based research: assessing partnership approaches to improve public health. Annu. Rev. Publ. Health 19, 173-202

32. Roux, D.J. et al. (2006) Bridging the science-management divide: moving from unidirectional knowledge transfer to knowledge interfacing and sharing. Ecol. Soc. 11, 4
33. Carberry, P.S. (2001) Are science rigour and industry relevance both achievable in participatory action research? Agric. Sci. 14 22-28

34. Wortmann, C.S. et al. (2005) Farmer research: conventional experiences and guidelines for alternative agriculture and multi-functional agro-ecosystems. Renewable Agric. Food Syst. 20, 243-251

35. Leigh, P. (2005) The ecological crisis, the human condition, and community-based restoration as an instrument for its cure. Ethics Sci. Environ. Polit. 5, 3-15

36. Cabin, R.J. et al. (2010) Bridging restoration science and practice: results and analysis of a survey from the 2009 Society for Ecological Restoration International Meeting. Restoration Ecol. 18, 783-788

37. Morandi, B. et al. (2014) How is success or failure in river restoration projects evaluated? Feedback from French restoration projects. J. Environ. Management 137, 178-188

38. Luoma, J.R. (2012) China's Reforestation Programs: Big Success or Just An Illusion? Yale e360

39. Samson, M.S. and Rollon, R.N. (2008) Growth performance of planted mangroves in the Philippines: revisiting forest management strategies. Ambio 37, 234-240

40. Perring, M.P. et al. (2015) Soil-vegetation type, stem density and species richness influence biomass of restored woodland in south-western Australia. Forest Ecol. Management 344, 53-62

41. van Wilgen, B.W. et al. (2012) Challenges in invasive alien plant control in South Africa. S. Afr. J. Sci. 108, 145

42. Moreno-Mateos, D. et al. (2012) Structural and functional loss in restored wetland ecosystems. PLoS Biol. 10, e1001247 